\title{
APLICAÇÃO DA LEI PENAL E SUMULA 231 DO STJ: INCOMPATIBILIDADE DIANTE DO PRINCÍPIO DA LEGALIDADE
}

\author{
CRIMINAL LAW APPLICATION AND PRECEDENT 231 OF THE STJ: \\ INCOMPATIBILITY UNDER THE LEGALITY PRINCIPLE
}

\section{Suzana Cysneiros Sampaio}

\section{Centro Universitário Doutor Leão Sampaio} E-mail: s.cys@outlook.com

\section{RESUMO}

A pesquisa ora apresentada busca analisar quais são as controvérsias existentes nos debates que envolvem a validade da súmula 231 do STJ, diante do sistema trifásico adotado para a aplicação da lei penal. Busca, ainda, analisar os argumentos contrários e os favoráveis à súmula, assim como observar aspectos doutrinários, legais e jurisprudenciais que envolvem a sua aplicação. A pesquisa pautada na problemática ante exposta justifica-se na medida em que se faz necessário analisar a validade da aplicação da súmula 231, levando em consideração seus pontos controversos, no que tange o atual sistema de aplicação da lei penal presente no Código Penal de 1940. Ademais, a pesquisa justifica-se ainda no sentido de que se apresenta como essencial indicar o contraste presente nos pressupostos que fundamentam a súmula com os princípios norteadores do direito penal, sobretudo, o princípio da legalidade. Assim sendo, o objetivo geral da investigação foi observar a divergência existente entre o sistema trifásico da aplicação da lei penal, adotado pela atual legislação penal e a aplicação da súmula 231 do STJ, à luz do princípio da legalidade. Para o desenvolvimento de tal estudo, a metodologia empregada assenta-se nos métodos de abordagem dedutivo e qualitativo, auxiliados pelas técnicas de pesquisa bibliográfica, jurisprudencial e de análise documental. Destarte, como decorrência de tal pesquisa, foi possível verificar que os argumentos que fundamentam a juricidade da súmula 231 estão sob a égide de uma legislação que de há muito não vigora no ordenamento jurídico brasileiro. Isto posto, é pertinente afirmar que as teses que justificam a existência da referida súmula estão pautadas, ainda, numa interpretação distorcida de dispositivos legais e princípios norteadores do direito penal, apresentando-se como uma tendência interpretativa contra legem.

Palavras-chave: Princípio da legalidade; sistema trifásico; súmula 231 do STJ.

\section{ABSTRACT}

The research now presented seeks to analyze what are the controversies existing in the debates that involving the validity of STJ Precedent 231, in view of the three-phase system adopted for the application of criminal law. It also seeks to analyze the arguments against and in favor of the precedent, as well as observe doctrinal, legal and jurisprudential aspects that involve its application. The research based on the problem exposed above is justified insofar as it is necessary to analyze the validity of the application of precedent 231, taking into account its controversial points, with regard to the guiding principles of criminal law, above all, the principle of legality. Furthermore, the research is still justified in the sense that it is essential to indicate the contrast present in the assumptions that support the summary with the current penal law enforcement system contained in the 1940 Code. Therefore, the general objective of the investigation was observing the divergence existing between the three-phase system of criminal law enforcement, adopted by the current criminal law and the application of Precedent 231 of the STJ, in light of the principle of legality. For the development of such a study, the methodology used is based on the deductive and qualitative approach methods, aided by bibliographic, jurisprudential and document analysis techniques. Thus, as a result of such research, it was possible to verify that the arguments that support the legality of precedent 231 are under the aegis of legislation that has not been in force in the Brazilian legal system for a long time. That said, it is pertinent to state that the theses that justify the existence of the aforementioned summary are still based on a distorted interpretation of legal provisions and guiding principles of criminal law, presenting themselves as an interpretative tendency against legem.

Keyword: Principle of legality; three-phase system; Precedent 231 of the STJ. 


\section{V.10 N.1 (2022) ISSN: 2317-434X}

\section{INTRODUÇÃO}

O princípio da legalidade está fundamentado na necessidade de impedir o poder estatal de punir arbitrariamente e traduz-se no preceito latino "nullum crimen, nulla poena sine lege". Tal princípio está consagrado na Constituição Federativa do Brasil, de 1988, em seu art. $5^{\circ}$, XXXIX sob o mandamento de que "não há crime sem lei anterior que o defina, nem pena sem prévia cominação legal". Outrossim, o princípio da legalidade também encontra respaldo no inciso II do art. $5^{\circ}$ da $\mathrm{CF} / 88$. Assim, o princípio da legalidade representa um grande avanço para a consolidação de um sistema jurídico transparente e comprometido com a justiça, especialmente quando presente no âmbito penal.

Nesse sentido, o presente artigo científico tem como propósito investigar a legitimidade da aplicação da súmula 231 do STJ diante do sistema trifásico adotado para a aplicação da lei penal, conceituado no art. 68 do Código Penal Brasileiro de 1940, haja vista que a interpretação da súmula, para parte considerável da doutrina, é contra legem, ferindo, assim, o princípio da legalidade, norteador do Direito Penal. À vista disso, a presente pesquisa baseia-se no seguinte questionamento: Como o princípio da legalidade pode auxiliar no entendimento sobre a incompatibilidade da súmula 231 do STJ com o sistema trifásico de aplicação da lei penal adotado pelo CPB?

Nesse seguimento, a análise do objeto de estudo ora citado, justifica-se no plano teórico na medida em que se faz necessário analisar a validade da aplicação da súmula 231, levando em consideração seus pontos controversos, no que tange ao atual sistema de aplicação da lei penal presente no Código de 1940. Ademais, a pesquisa justifica-se ainda no sentido de que se apresenta como essencial indicar o contraste presente nos pressupostos que fundamentam a súmula com os princípios norteadores do direito penal, sobretudo, o princípio da legalidade.

Destarte, a pesquisa aqui apresentada tem como objetivo geral observar a divergência existente entre o sistema trifásico da aplicação da lei penal, adotado pelo CPB e a aplicação da súmula 231 do STJ, à luz do princípio da legalidade. Não obstante, pretende-se como objetivos específicos analisar o processo de formação da súmula 231 do STJ e expor os motivos pelos quais esta não é condizente com o art. 68 do Código Penal vigente; promover uma discussão acerca das consequências geradas pela aplicação da súmula 231 na segunda fase da dosimetria da pena e; identificar os posicionamentos doutrinários favoráveis e contrários à aplicação da súmula.

O presente artigo será estruturado em três partes a fim de promover uma divisão didática que permita o esclarecimento dos pontos fundamentais do problema identificado. Isto posto, incialmente será apresentado o conceito de princípio da legalidade, assim como será explanado sobre a sua importância como norte do direito penal. Não obstante, irá se fazer uma explanação sobre as fases da dosimetria, atentando para a segunda fase de aplicação da lei penal. Em seguida, parte-se para o exame da súmula 231 do STJ, levando em consideração aspectos doutrinários e jurisprudenciais favoráveis à sua aplicação. Por fim, será feita uma análise da influência prática da súmula 231 no processo de aplicação da lei penal, dando ênfase para a intervenção desta na mitigação de princípios basilares do direito penal, assim como a demonstração de sua inaplicabilidade perante o atual sistema jurídico penal.

\section{METODOLOGIA}

À vista disso, a presente pesquisa apresenta-se como um tipo exploratório, tendo por base que se pretendeu expor as problemáticas que assolam o enredo doutrinário e jurisprudencial dos aspectos teóricos e práticos suscitados em razão da súmula 231 do Superior Tribunal de Justiça. Com o fim de cumprir com os objetivos delineados, o estudo ora proposto foi realizado por meio do método qualitativo, conjugado com a análise dedutiva. Tal escolha se justifica na importância da interpretação integral do ordenamento jurídico brasileiro, a fim de que se demonstrasse a incompatibilidade da súmula 231. Ademais, foram aplicadas as técnicas de pesquisa bibliográfica, por meio da leitura de livros doutrinários e artigos científicos, com o ensejo de corroborar com os argumentos favoráveis e os divergentes da aplicação da referida súmula. Por fim, o estudo foi complementado pela análise de dispositivos da Constituição Federal de 1988 e do Código Penal, decretolei no 2.848, de 7 de dezembro de 1940, assim como pelo exame e interpretação da jurisprudência do Supremo Tribunal Federal e do Superior Tribunal de Justiça.

\section{LEGALIDADE E DOSIMETRIA: ASPECTOS INICIAIS}

Dentro de um ordenamento jurídico que preza pela coesão e harmonia, há sempre um conjunto de princípios que o regem. Os princípios representam tanto uma garantia para os cidadãos, quanto uma orientação a ser seguida pelos poderes de um Estado Democrático de Direito. Dentre os princípios que norteiam o direito penal, cabe analisar nesse cenário a importância do princípio da legalidade, o qual se traduz em um dos mais valiosos sustentáculos para a proteção do ideal de segurança 


\section{V.10 N.1 (2022) ISSN: 2317-434X}

jurídica, haja vista que representa um verdadeiro obstáculo para as ingerências e o uso indevido do ordenamento jurídico para fins de intervenções ilegítimas na vida privada dos indivíduos. Dessa forma, a lei deve ser produzida e interpretada em sua forma mais precisa, a fim de que aquele que julga não incorra em equívocos, não raro, oportunamente nefastos.

A origem do princípio da legalidade remonta à Inglaterra absolutista, cujo panorama de frequentes violações criou a necessidade de estabelecer um sistema baseado numa legislação que não estivesse sob a égide da vontade arbitrária do rei (NUCCI, 2020, p. 62). Como explica Guilherme de Souza Nucci (2020, p. 64) o princípio foi conservado pelo modelo latino, atribuído ao escritor Feuerbach": "nullum crimen, nulla poena sine praevia lege", o qual inspirou diversas legislações e ainda reverbera sua influência no mundo jurídico moderno.

No contexto constitucional brasileiro, pode-se afirmar que na redação da Constituição do Império de 1824, o princípio da legalidade foi conceituado de forma combinada com outros princípios, tais como o princípio do juiz natural e o princípio do devido processo legal. Em contrapartida, a Constituição de 1937, que marca o período conhecido como Estado Novo contempla o princípio da legalidade de forma mais vinculada ao princípio da anterioridade da lei penal. No que tange a Carta de 1967, enunciava o seu comando legal, quanto ao princípio da legalidade, como um ideal ligado ao princípio da retroatividade da lei penal mais benéfica ao réu. Destarte, nota-se que a via geral definida na Carta Política de 1824 serviu de molde para as seguintes definições do princípio da legalidade pelas Constituições futuras, mesmo com pequenas modificações no que tange a influência de princípios (ZAFFARONI; BATISTA; ALAGIA; SLOKAR, 2011, p. 202). Quanto a Constituição da República Federativa do Brasil de 1988, o princípio da legalidade está presente em seu art. $5^{\circ}$, II e XXXIX. Dessa forma, constata-se que tal princípio é inerente ao constitucionalismo brasileiro.

Assim como na Lei Maior, o princípio da legalidade também está expressamente previsto no Código Penal de 1940 , em seu art. $1^{\circ}$ sob a fórmula de que "não há crime sem lei anterior que o defina. Não há pena sem prévia cominação legal". Dessa forma, verifica-se que tal comando legal veda a criação de lei que puna determinado fato depois de sua ocorrência (NUCCI, 2020, p. 147), sendo o princípio da anterioridade da lei penal uma das bases do princípio da legalidade. Ainda sobre o princípio da legalidade, a doutrina o desdobra em mera legalidade e legalidade estrita, sendo a primeira direcionada para a atuação dos juízes, na fase de criminalização secundária, e a primeira voltada para a atividade legislativa, no que tange o processo de criminalização primária. No contexto hodierno, não é viável apenas falar-se de uma em detrimento da outra, mas sim analisar a legalidade sob esses dois aspectos, assim para Guilherme de Souza Nucci (2020, p.147) "um crime deve estar descrito em lei, mas bem detalhado (taxativo), de modo a não provocar dúvidas e questionamentos intransponíveis". Ademais, cumpre salientar que a Constituição reserva privativamente à União legislar sobre matéria penal, emanando tal afirmação de seu art. 22, I. Tal preceito justifica-se na necessidade de o Estado tomar para si a responsabilidade pela criação de normas de conteúdo tão sensível e propícias a causar intervenções inconvenientes na vida particular dos cidadãos.

Posto isto, é relevante discorrer sobre o comando legal que dispõe sobre o procedimento a ser seguido para a correta aplicação da pena. A aplicação da lei penal da forma como está presente no Código Penal de 1940 está, procedimentalmente, ligada ao princípio da individualização da pena, princípio este consagrado em patamar constitucional e enunciado nos incisos XXXIX e XLVI do art. $5^{\circ}$ da Magna Carta. Doutrinariamente, existiam duas correntes que buscavam influenciar a redação do art. 68 do Código Penal, a teoria de Nélson Hungria e a de Roberto Lyra. Segundo Damásio de Jesus, para o primeiro autor, o processo de aplicação da lei penal deveria seguir três operações para a sua correta aplicação, primeiramente deveria encontrar a pena abstrata, com base na cominação feita pelo legislador e a essa pena abstratamente cominada, aditar as outras etapas da dosimetria, passando pela fase de agravação ou atenuação e chegando a pena concreta (JESUS, 2015, p. 635). Em contrapartida, o mesmo doutrinador considera que para Roberto Lyra a pena deveria ser aplicada com base em apenas duas fases, na primeira fase o juiz decidiria sobre a pena-base com fundamento no quantum cominado em conjunto com as agravantes e atenuantes, logo após faria incidir as causas de aumento e de diminuição.. Prescindindo do mérito das discussões que envolvem tais correntes doutrinárias, percebemos por uma análise do art. 68 da atual codificação penal, a escolha em favor da tese de Nélson Hungria (JESUS, 2015, p. 636). Assim, o art. 68 do CPB declara:

A pena-base será fixada atendendo-se ao critério do art. 59 deste Código; em seguida serão

1 Paul Johann Anselm Feuerbach, em sua obra intitulada "Lehrbuch des gemeinen in Deutschland gültigen peinlichen Rechts". 
V.10 N.1 (2022) ISSN: 2317-434X

consideradas as circunstâncias atenuantes e agravantes; por último, as causas de diminuição e deaumento (BRASIL, 1940).

Dessa forma, temos que o atual panorama legal de aplicação da lei penal é composto por três momentos que devem ser analisados separadamente. Inicialmente buscase computar a incidência das circunstâncias judiciais presentes no art. 59 do Código Penal, assim, deve o juiz observar a culpabilidade, os antecedentes, a conduta social, a personalidade do agente, os motivos, as circunstâncias e consequências do crime, bem como o comportamento da vítima, para que dessa maneira possa encontra a pena-base. A pena-base será o ponto de partida através do qual irá ser possível a incidência das outras fases da dosimetria (BITTENCOURT, 2020, p. 851). À vista disso, a pena base irá localizar-se mais próximo do mínimo legal da pena cominada ao crime, na medida em que concorrerem mais circunstâncias judiciais favoráveis, sendo a recíproca verdadeira, como leciona o professor Cézar Roberto Bittencourt:

Se algumas circunstâncias forem desfavoráveis, deve afastar-se do mínimo; se, contudo, o conjunto for desfavorável, pode aproximar-se do chamado termo médio, que, segundo a velha doutrina nacional, é representado pela média da soma dos dois extremos, quais sejam, limites mínimo e máximo cominados. De regra, o cálculo da pena deve iniciar a partir do limite mínimo e só excepcionalmente, quando as circunstâncias do art. 59 revelarem especial gravidade, se justifica a fixação da pena-base afastada do mínimo legal. (BITTENCOURT,2020, p. 851).

Logo após o estabelecimento da pena-base, partese para a análise da possibilidade da incidência de agravantes e atenuantes em relação à pena-base definida, sendo tal procedimento considerado como a segunda fase da dosimetria, a qual merece especial destaque, haja vista a sua imprescindível importância para o cumprimento eficaz dos objetivos do presente trabalho. A segunda fase da dosimetria da pena configura-se por ser o momento em que o juiz observará a existência das circunstancias legais, presentes nos artigos 61, 62 e 65 do CPB (BITTENCOURT, 2020, p. 854). A grande discussão em torno da segunda fase de aplicação da pena, diz respeito à divergência doutrinária presente na possibilidade da redução da pena aquém do mínimo legal.

Como terceira e última etapa tem-se a descrição da pena definitiva, nesta etapa serão observadas as causas de aumento e de diminuição, as quais também irão incidir sobre a pena até o momento encontrada, havendo a possibilidade dessa pena definitiva corresponder a pena- base, no caso de não recair sobre a conduta do agente nenhuma agravante ou atenuante além de não incidir nenhuma causa de aumento ou de diminuição (BITTENCOURT, 2020, p. 858).

Portanto, com o panorama legal e principiológico traçado, depreende-se que o sistema normativo penal, no que corresponde à sistemática de aplicação da pena está fundamentado em parâmetros constitucionais, tais como o princípio da individualização da pena, e estando justificado em lei, deve ser regularmente seguido, fazendo jus ao princípio da legalidade. Isto posto, parte-se para o estudo da Súmula 231 do STJ e suas implicações com as bases principiológicas e legais no contexto jurídico brasileiro.

\section{ANÁLISE DA SÚMULA 231 DO STJ}

A súmula 231, publicada no ano de 1999 pelo Superior Tribunal de Justiça, enuncia que: "A incidência da circunstância atenuante não pode conduzir à redução da pena abaixo do mínimo legal". Como outrora analisado, as circunstancias atenuantes irão incidir na segunda fase de aplicação da pena. A criação da súmula deu-se baseada em diversos precedentes que colocaram em destaque a discussão sobre a possibilidade de redução da pena abaixo do mínimo legal cominado. À vista disso, dentre os precedentes que engendraram a súmula, está o REsp N. 7.287-PR (91.4812), pelo qual o Relator, O Sr. Ministro William Patterson expôs em seu voto que:

Ao ser reduzida a pena do réu [...] importou isso em fixar sanções inferiores ao mínimo legal, o que não é possível, por força do disposto no art. 65, IV, d, 67, 68 e 71, do Código Penal, além de contrariar a orientação jurisprudencial de outros Tribunais, inclusive o Egrégio Supremo Tribunal Federal.

Não obstante, assegura o Ministro e Relator do REsp n ${ }^{\circ}$. 146.056-RS (97.60498-5), o Sr. Felix Fischer que:

Desde a elaboração do C. Penal de 40, passando pelas diversas alterações, até se atingir a modificação ampla realizada pela Lei $n$. 7.209/1984, nunca predominou - nem sequer mereceu destaque - o entendimento de que as agravantes e atenuantes (ao contrário das majorantes e minorantes) pudessem levar a pena privativa de liberdade para fora dos limites previstos em lei.

Para Bittencourt, o teor da súmula está baseado no 


\section{V.10 N.1 (2022) ISSN: 2317-434X}

antigo parágrafo único do art. 48 do Código Penal de 1940, o qual tratava sobre as circunstancias atenuantes, antes da reforma pela qual passou o código com a lei n. 7.209/84, assim, dispunha o revogado dispositivo:

Parágrafo único. Se o agente quis participar de crime menos grave, a pena é diminuída de um terço até metade, não podendo, porém, ser inferior ao mínimo da cominada ao crime cometido (BRASIL,1940).

Nesses termos, percebe-se que o dispositivo acima mencionado é o principal vetor de influência no que tange ao nascimento da súmula. Entretanto, com a vigência da Lei n. 7.209, foi inserido no Código penal os art. 59 e 68, os quais tratam sobre a fixação e cálculo da pena, respectivamente:

Art. 59 - O juiz, atendendo à culpabilidade, aos antecedentes, à conduta social, à personalidade do agente, aos motivos, às circunstâncias e consequências do crime, bem como ao comportamento da vítima, estabelecerá, conforme seja necessário e suficiente para reprovação e prevenção do crime:

[...]

Art. 68 - A pena-base será fixada atendendo-se ao critério do art. 59 deste Código; em seguida serão consideradas as circunstâncias atenuantes e agravantes; por último, as causas de diminuição e de aumento.

Outrossim, relativamente ao posicionamento doutrinário, mesmo com a revogação do art. 48, o qual se amparava a redação da súmula 231 , esta não perde seu sentido originário, haja vista que para parte da doutrina a nova orientação legislativa também tende a reafirmar o posicionamento sumulado. Assim, para Damásio de Jesus:

Em face de uma circunstância agravante ou atenuante, nem sempre a aplicação de seu efeito é obrigatória. Isso porque, tratando-se de circunstâncias legais genéricas, a pena não pode ser fixada aquém do mínimo ou além do máximo. (JESUS, 2015, p. 637).

Não obstante, seguindo mesma a orientação sumulada, a doutrina de Guilherme de Souza Nucci assevera que:

As atenuantes não fazem parte do tipo penal, de modo que não têm o condão de promover a redução da pena abaixo do mínimo legal. Quando o legislador fixou, em abstrato, o mínimo e o máximo para o crime, obrigou o juiz a movimentar-se dentro desses parâmetros, sem possibilidade de ultrapassá-los, salvo quando a própria lei estabelecer causas de aumento ou de diminuição (NUCCI, 2021, p. 433)

Neste cenário, ainda apresenta-se como relevante destacar que os argumentos predispostos à aceitação da súmula estão baseados no princípio da tripartição dos poderes conjugado com o princípio da reserva legal. Isto se dá tendo em vista que o julgador não pode ir de encontro com o estabelecido pelo poder legislativo, tendo aquele o dever de aplicar a lei ao caso concreto, sem adaptações distantes do que observa o texto legal (FREIRE, 2016, p. 28), configurando a inadmissibilidade da transposição do limite mínimo da pena, uma característica indeclinável das circunstâncias judiciais (MIRABETE, 2021, p. 329). Assim não havendo nenhuma norma que assegure expressamente a admissibilidade da atenuação da pena abaixo do mínimo legal, não há que se falar em validade de alegação contrária. Nesse sentido é o entendimento de Paulo Cézar Busato, o qual sustenta, após revelar argumentosfavoráveis e desfavoráveis à sumula, que:

Resultam improcedentes os argumentos contrários à Súmula. Finalmente, se não por essas razões, ao menos por coerência sistemática e equilíbrio não é possível pretender essa alteração unilateral de regras de fixação de pena sem flagrante prejuízo a um mínimo de segurança jurídica e sem reconhecer a abertura de portas ao arbítrio e à instalação de privilégios (BUSATO, 2020, p. 681)

Pela mesma via de posicionamentos favoráveis, o Supremo Tribunal Federal ratificou a validade do teor da súmula 231 por meio do seu HC 100371/CE:

HABEAS CORPUS. PENAL. DOSIMETRIA DA PENA. AUSÊNCIA DE FUNDAMENTAÇÃO. MATÉRIA NÃO SUBMETIDA ÀS INSTÂNCIAS INFERIORES. DUPLA SUPRESSÃO DE INSTÂNCIA. PENA-BASE FIXADA ACIMA DO MÍNIMO LEGAL. DECISÃO FUNDAMENTADA EM CIRCUNSTÂNCIAS JUDICIAIS DESFAVORÁVEIS. FIXAÇÃO DA PENA ABAIXO DO MÍNIMO LEGAL. IMPOSSIBILIDADE. ORDEM NÃO CONHECIDA.

[...]

III - É firme a jurisprudência da Suprema Corte no sentido de que, ao contrário do que ocorre com as causas de diminuição, as circunstâncias atenuantes não podem reduzir a pena aquém do 
V.10 N.1 (2022) ISSN: 2317-434X

mínimo legal. IV - Habeas corpus não conhecido.

Em contrapartida, há parcela considerável da doutrina que não acolhe tal posicionamento, a exemplo de Cézar Roberto Bittencourt e Eugênio Pacelli, rejeitando a tese da validade dos fundamentos da súmula 231 no ordenamento jurídico brasileiro. Parte-se agora para a análise da desarmonia jurídica motivada pela súmula 231 .

\section{INCOMPATIBILIDADE DA SÚMULA 231 COM O ORDENAMENTO JURÍDICO BRASILEIRO}

Com base em princípios constitucionais que norteiam o direito penal, assim como no sistema escolhido para a aplicação da lei penal, há argumentos em sentido contrário que tendem a afastar a legitimidade do teor da súmula 231, os quais se passarão a expor. Dessa maneira, a orientação que vai de encontro ao comando sumulado está fundamentada no texto legal do art. 65 do Código Penal, o qual assegura que as circunstâncias que nele constam, sempre que incidirem sobre o caso concreto, devem atenuar a pena, condicionando sua eficácia à segunda fase da dosimetria da pena. Por ser uma garantia penal, a sua inaplicabilidade, quando for possível no caso em concreto a sua incidência, é uma atitude que viola um direito público subjetivo daquele que está sendo julgado, o distanciando de um sistema penal preocupado com a aplicação justa da lei (BITTENCOURT, 2020, p. 856). Argumenta-se, ainda, sobre o fato de não haver em todo o conjunto que constitui o ordenamento jurídico pátrio, norma proibitiva no sentido de obstar que o reconhecimento de atenuantes, na segunda fase da aplicação da pena, estabeleça a pena aquém do mínimo legal. Pacelli e Callegari (2020, p. 474) entendem que o reconhecimento da atenuante para estabelecer a pena abaixo do mínimo cominado, "não viola qualquer norma legal ou constitucional" (PACELLI; CALLEGARI, 2020, 476).

Não obstante, é válido ressaltar o entendimento de que o antigo parágrafo único do art. 48 do CPB disciplinava matéria de diminuição da pena, haja vista que o comando legal previa que "a pena é diminuída de um terço até metade" devendo ser interpretado de acordo com a terceira fase da dosimetria, não sendo topograficamente correto o reconhecer como uma circunstância atenuante genérica. Assim, tendo por base que tal mecanismo legal é tido como a principal condicionante da súmula 231 do STJ, tem-se que o seu teor normativo tende a ser uma espécie de analogia, sendo tal prática, vedada no direito penal, quando agrava a situação do réu. Outrossim, a analogia serve para complementar e elucidar questões obscuras no texto da lei, não sendo o caso das normas que regem o atual contexto normativo de aplicação da lei penal. Assim, para Nucci (2020, p. 149):

Para assegurar a eficácia do princípio da legalidade é preciso manter o equilíbrio e o meiotermo: nem analogia nem tipos extremamente vagos e genéricos. Em ambos os casos, estar-se-ia preterindo a aplicação do preceito constitucional da reserva legal.

Isto posto, dar margem para o uso do instituto da analogia, por meio da aplicação da súmula 231 do STJ, atinge preceitos de ordem garantista, além de ser uma grave afronta ao princípio da legalidade, orientador do direito penal. Dessa forma, Fabretti e Smanio, sustentam que permitir o uso da analogia in malam partem:

Violaria, certamente, não só a segurança jurídica do cidadão - que como já dissemos tem o direitogarantia de saber o que pode ou não fazer , mas também os postulados do próprio Estado Democrático de Direito, que sempre deve ter o Direito Penal como um limite a sua própria atuação perante o indivíduo (FABRETTI; SMANIO, 2019, p. 129).

Ademais, aos que são contrários à aplicação da súmula, destaca-se, ainda, o seu caráter contra legem, por considerar que o conteúdo desta é frontalmente contrário ao que dispõe a legislação infraconstitucional, além de ferir princípios constitucionais (FREIRE, 2016, p. 24).

Diante disso, contrapondo os argumentos prósúmula, reputa-se como inteligível a primeira parte da redação do art. 68 do Código Penal, o qual por um processo de interpretação apurado torna patente que se dirige somente à primeira fase da dosimetria, assim, deve ser interpretado no sentido de influenciar somente o cálculo da pena-base. Essa exegese é possível em razão de o art. 68 ser estruturado em três orações, sendo cada uma condizente com as fases do sistema tripartido de aplicação da lei penal, devendo-se fazer uma análise autônoma de cada uma. Assim, o art. 68 é preciso ao enunciar que "a pena-base será fixada atendendo-se ao critério do art. 59 deste Código", e somente em momento posterior é que se fará uma análise da incidência de atenuantes ao caso concreto, não sendo idôneo o posicionamento que intenta em aplicar os comandos dos inciso I e II do art. 59 à segunda fase da dosimetria, pelos quais o juiz deve estabelecer a pena-base atentando-se para:

I - as penas aplicáveis dentre as cominadas; II - a quantidade de pena aplicável, dentro dos limites previstos. 


\section{V.10 N.1 (2022) ISSN: 2317-434X}

Portanto, não há viabilidade para que tal posicionamento prospere no ordenamento jurídico brasileiro, haja vista que o texto legal é claro no sentido de apontar que os limites mínimo e máximo estão restritos à pena-base, ou seja, à primeira fase de aplicação da pena (TABET, 2017, p.238). Desta maneira, após ser estabelecida a pena-base, não há lei que delimite a aplicação das circunstancias atenuantes sobre a pena estabelecida, podendo esta ser assentada abaixo do mínimo legal. Neste sentido aponta o HC 9.719/SP:

\begin{tabular}{lcr} 
PENAL. PENA. INDIVIDUALIZAÇÃO. & \multicolumn{2}{c}{ MÍNIMO. } \\
PENA-BASE. & GRAU & \multicolumn{2}{c}{ ATENUANTE. } \\
CIRCUNSTÂNCIA & & ATENUÃ \\
INCIDÊNCIA. REDUÇA & ABAIXO DO \\
MÍNIMO LEGAL. & &
\end{tabular}

No processo trifásico de individualização da pena é possível a sua fixação definitiva abaixo do mínimo legal na hipótese em que a pena-base é fixada no mínimo e se reconhece a presença de circunstância atenuante, em face da regra imperativa do art. 65, do Código Penal, que se expressa no comando literal de que tais circunstâncias sempre atenuam a pena. - Habeascorpus concedido.

Consoante o exposto, vale ressaltar que a composição da súmula 231 do STJ, obsta, ainda, a eficácia plena do princípio da individualização da pena. $\mathrm{O}$ princípio da individualização da pena está previsto no XLVI, do art. $5^{\circ}$ da Constituição Federal e no art. 34 do Código Penal. Isso se dá porque na medida em que não se faz uma aplicação correta em direção ao comando legal, não se pode falar que houve justiça na decisão, dessa forma se está dando ao indivíduo uma pena que ele não merece, fazendo-o pagar por uma pena desmensurada ao caso em concreto (ROCHA, 2020, p. 27). Ademais, a pena é uma representação de uma imposição de castigo, a fim de intimidar o indivíduo, reafirmando, assim, a função do direito penal, encaminhando-se para uma ressocialização do indivíduo apenado (NUCCI, 2020, p. 340). Assim, para corresponder a uma pena justa, a decisão do julgador deve observar o princípio da individualização da pena.

Como um desdobramento do princípio da individualização da pena, o princípio da isonomia também exerce papel relevante quando se trata do estudo da súmula 231 do STJ, tendo por base que esta também interfere no pleno emprego desse princípio no âmbito da aplicação da lei penal. Destarte, pelo princípio da isonomia, na seara penal, entende-se que deve o magistrado agir de modo a reduzir as desigualdades existentes na lei penal. À vista disso e tendo como base que as condutas tipificadas como crime não se dão de formas idênticas, podendo ser semelhantes, mas jamais podendo uma conduta corresponder aos mesmos elementos e circunstâncias de outra, julgar de forma análoga casos diferentes é incorrer em erro e submeter o apenado a uma sentença injusta, ainda mais quando existe preceito legal que orienta a sempre aplicar atenuantes quando essas forem possíveis ao caso. Assim, Eugênio Pacelli e André Callegari, no que diz respeito ao princípio da isonomia e o teor da súmula 231, asseveram que:

Se todos os homens devem ser tratados e tidos
como iguais, e se cabe ao Direito, não só
consagrar tais expectativas, mas avançar e
permitir a concretização dessa promessa, a
igualdade parece ser a via preponderante na
interpretação, sobretudo, das normas proibitivas e
punitivas. Assim, todos quantos estejam
submetidos à presença de uma circunstância
atenuante, ou seja, em situação legalmente
qualificada como de menor reprovabilidade,
devem-se beneficiar desse juízo, atenuando a
pena a eles cominada no tipo. Nesse passo, o
limite mínimo cominado ao tipo penal não poderá
impedir que todasas pessoas que tenham agido em
situação de atenuação da pena recebam o mesmo
tratamento. Há que se lembrar que o Código Penal
determina que as circunstâncias previstas no art.
65 sempre atenuam a pena. Ou seja, para além do
fundamento principiológico da igualdade, há
também o argumento legal (PACELLI;
CALLEGARI, 2020, p. 475).

Entretanto, é o princípio da legalidade o mais atingido pela aplicação da súmula 231 do STJ, haja vista que o comando legal não é respeitado, tanto no que tange aos princípios constitucionais, quanto às normas que orientam as fases da dosimetria. Vale destacar que o subprincípio da legalidade, a taxatividade, é manifestamente violado pela súmula, tendo por fundamento que tal subprincípio caracteriza-se por não permitir que a lei abuse de "cláusulas gerais e conceitos indeterminados" (FABRETTI; SMANIO, 2019, p.125), nessa orientação, o comando legal, previsto no art. 65 , ao utilizar a expressão "sempre" está, de forma inequívoca, impondo a aplicação das atenuantes a todos os casos em que for possível a sua incidência, não deixando margem para interpretação oposta, a qual configura verdadeira violação a taxatividade da lei penal, assim, afirma Bittencourt:

Em síntese, não há lei proibindo que, em decorrência do reconhecimento de circunstância atenuante, possa ficar aquém do mínimo cominado. Pelo contrário, há lei que determina (art. 65), peremptoriamente, a diminuição da pena 


\section{V.10 N.1 (2022) ISSN: 2317-434X}

em razão de uma atenuante, sem condicionar seu reconhecimento a nenhum limite (BITTENCOURT, 2020, p, 856).

Outrossim, a legalidade deve ser compreendida como uma garantia para o indivíduo, não para o Estado na justificação da sua ingerência nas normas e princípios penais. Isto posto, uma vez que o sistema de aplicação da pena escolhido foi o sistema de Nelson Hungria, a referida súmula mostra-se incompatível com o art. 68 do $\mathrm{CP}$, e consequentemente, com o sistema trifásico de aplicação da pena, tendo em consideração que o art. 59, I e II do CP refere-se apenas à pena-base, não correspondendo à segunda fase da dosimetria. Entretanto, é no sistema bifásico que as circunstâncias judiciais e legais são analisadas na mesma etapa, deste modo, a súmula é frontalmente contrária ao sistema adotado pelo ordenamento jurídico, quanto ao sistema escolhido para a aplicação da lei penal, adotando uma tese que de há muito foi rejeitada (TABET, 2017, p. 238).

\section{CONCLUSÃO}

Com base no exposto ao longo da pesquisa, tornase manifesto que os dispositivos penais que regulamentam a dosimetria da pena não dão margem a interpretações deturpadas, tal como o presente na súmula 231 do STJ, sendo o comando presente no art. 68 do CPB inequívoco, no sentido de nortear as fases de aplicação da lei penal, devendo os incisos I e II do art. 59 conduzirem unicamente a primeira fase da dosimetria, não interferindo de qualquer forma no processo de incidência das circunstancias judiciais.

Não obstante a súmula 231 ser fundamentada em um dispositivo revogado, nota-se que a restrição contida no parágrafo único do antigo instrumento legal é reservada somente ao caso de a vontade do agente ter sido a de participar de crime menos grave, sendo qualquer outra forma de ampliação interpretativa, no intuito de abranger todos os casos em que a pena deva ser aplicada abaixo do mínimo legal, uma interpretação in malan partem, além de configurar também verdadeira analogia, proibida no âmbito do direito penal.

À vista disso, por o entendimento sumulado ser frontalmente contrário ao previsto legalmente, realiza-se a mitigação de princípios constitucionais que regem o sistema penal, degradando, como consequência, toda a cadeia normativa que pretende proporcionar ao indivíduo uma pena condizente com a sua ofensa.

Portanto, distante de pretender encerrar as discussões sobre a temática, a pesquisa ora apresentada objetiva demonstrar que a súmula, além de desmerecer a base principiológica que é arcabouço do direito penal, deslegitima o próprio sistema normativo penal, tendo por base que ao passo em que o julgador sentencia sem atentarse para a justiça da decisão, está transformando o direito penal em uma dogmática vazia e sem coerência lógica com aquilo que o originou: livrar o indivíduo do arbítrio do soberano. No direito penal, a soberania não está apenas na letra da lei, mas acima de tudo, na coerência de sua aplicação.

\section{REFERÊNCIAS}

BITENCOURT, Cezar Roberto. Tratado de Direito Penal: parte geral: arts. $1^{\circ}$ a 120. 26. ed. São Paulo: Saraiva Educação, 2020. 1072 p.

BRASIL. Constituição (1988). Constituição da República Federativa do Brasil. Disponível em:<http://www.planalto.gov.br/ccivil_03/constituicao/constit uicaocompilado.htm>. Acesso em: 19 mar. 2021.

Supremo Tribunal Federal. HC: $100371 \mathrm{CE}$, Relator: Min. RICARDO LEWANDOWSKI, Data de Julgamento: 27/04/2010, Primeira Turma, Data de Publicação: 21/05/2010

BUSATO, Paulo César. Direito penal: parte geral, volume 1 5. ed. - são paulo: Atlas, 2020. 792 p.

Decreto Lei n. 2848, de 7 de dezembro de 1940. Código Penal. Disponível em: <http://www.planalto.gov.br/ccivil_03/decreto-

lei/del2848compilado.htm >. Acesso em: 19 mar. 2021.

Lei $n^{\circ}$ 7.209, de 11 de julho de 1984. Altera dispositivos do Decreto-Lei $n^{\circ} 2.848$, de 7 de dezembro de 1940 - Código Penal, e dá outras providências. Brasília, DF: Congresso Nacional, Disponível em: < http://www.planalto.gov.br/ccivil_03/leis/1980-

1988/17209.htm >. Acesso em: 19 mar. 2021.

. Superior Tribunal de Justiça. HC: 9.719-SP, Relator: Min. F. GONÇALVES, Data de Julgamento: 30/06/1999, Sexta Turma, Data de Publicação: 25/10/1999. Diário da Justiça. Seção 1. p. 130.

Superior Tribunal de Justiça. Recurso Especial $\mathbf{n}^{\mathbf{0}}$. 7.287-PR (91.4812). Sebastião Marques Cano. Ministério Público do Estado do Paraná. Relator: Ministro William 


\section{V.10 N.1 (2022) ISSN: 2317-434X}

Patterson. Brasília, DF, 16 de abril de 1991. Diário Oficial da União. Brasília, 06 maio 1991. Acesso em: 19 mar. 2021.

Superior Tribunal de Justiça. Recurso Especial N. 146.056-RS (97.60498-5). Ministério Público Federal. Siham Bowanani. Relator: Ministro Ministro Felix Fischer. Brasília, DF, 07 de outubro de 1997 . Diário Oficial da União. Brasília, 10 de novembro de1997. Acesso em: 19 mar. 2021.

Superior Tribunal de Justiça. Súmula n. ${ }^{\circ}$ 231. A incidência da circunstância atenuante não pode conduzir à redução da pena abaixo do mínimo legal. 1999. Disponível em<http://www.stj.jus.br/SCON/jt/toc.jsp>. Acesso em: 19 mar. 2021.

. Supremo Tribunal Federal. HC: 100371 CE, Relator: Min. RICARDO LEWANDOWSKI, Data de Julgamento: 27/04/2010, Primeira Turma, Data de Publicação: 21/05/2010.

FABRETTI, Humberto Barrionuevo; SMANIO, Gianpaolo Poggio. Direito penal: parte geral. 1. ed. - São Paulo: Atlas, 2019. 539 p.

FREIRE, Pedro Fellipe Araújo. A SÚMULA 231 DO STJ: UMA ANÁLISE PRINCIPIOLÓGICA. Juris Rationis: REVISTA CIENTÍFICA DA ESCOLA DE DIREITO, Natal, Rio Grande do Norte, v. 1, n. 9, p. 23-30, set. 2016. Semestral. Disponível em: https://repositorio.unp.br/index.php/juris/article/view/1483/908 . Acesso em: 19 mar. 2021.

JESUS, Damásio de. Direito penal, volume 1: Parte geral. $36^{\circ}$ ed. São Paulo: Saraiva, 2015.
MIRABETE, Julio Fabbrini. Manual de direito penal: parte geral: arts. $1^{\circ}$ a 120 do CP, volume $1-35$. ed. - São Paulo: Atlas, 2021. $461 \mathrm{p}$.

NUCCI, Guilherme de Souza. Curso de Direito Penal: parte geral: arts. $1^{\circ}$ a 120 do código penal. 4. ed. Rio de Janeiro: Editora Forense Ltda, 2020. 910 p.

NUCCI, Guilherme de Souza. Manual de Direito Penal, 17. ed. - Rio de Janeiro: Forense, 2021. 1123 p.

PACELLI, Eugênio; CALLEGARI, André. Manual de direito penal: parte geral - 6. ed. - São Paulo: Atlas, 2020. 619 p.

ROCHA, Márcio Cristiano da Silva da. INCONSTITUCIONALIDADE DA SÚMULA 231/STJ. 2020. 30 v. Artigo científico apresentado como requisito parcial para obtenção do título de Bacharel em Direito - Curso de Direito, Faculdade de Ciências Jurídicas e Sociais - Fajs do Centro Universitário de Brasília (Uniceub), Brasília, 2020.

TABET, Arthur Gomes. A INCONSTITUCIONALIDADE DA SÚMULA 231 DO STJ E SEUS REFLEXOS NA PROTEÇÃO DOS DIREITOS FUNDAMENTAIS. Jornal Eletrônico: Faculdades Integradas Vianna Júnior, Minas Gerais, n. 1, p. 230-246, jul. 2017. Disponível em: https://www.jornaleletronicofivj.com.br/jefvj/article/view/115. Acesso em: 19 mar. 2021.

ZAFFARONI, Eugenio Raúl; BATISTA, Nilo; ALAGIA, Alejandro; SLOKAR, Alejandro. Direito Penal Brasileiro: primeiro volume teoria geral do direito. 4. ed. Rio de Janeiro: Revan, 2011. 658 p. 